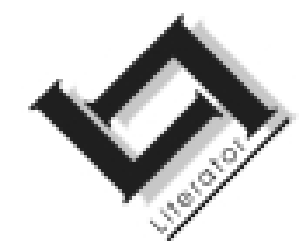

\title{
Doubling desire: The Yeatsian Daimon ${ }^{1}$
}

\author{
Nicholas Meihuizen \\ Department of English \\ University of Zululand \\ KWADLANGEZWA \\ E-mail: nctmeihu@pan.uzulu.ac.za
}

\section{Abstract \\ Doubling desire: The Yeatsian Daimon}

Through the agency of Daimonic desire, Yeatsian spiritualism repeats empirical existence. In positing a desire that extends beyond the limits of individual human life, Yeats denies the definitive value of an exclusive finitude, such as that perceived by Michel Foucault in The Order of Things (1974). If Yeats, involved in a qualified manner in an aspect of Foucault's analytic of finitude, is a modernist, he is related to that type Fredric Jameson calls the "anti-modern modernist" (Jameson, 1991:304), the modernist who reacts against modernisation.

In discussing Daimonic desire, then, it is congruous with a reading of Yeats to do so both from the perspective of the empirical realm of the "dying generations", and the spiritual realm of the "artifice of eternity". In the first case the Daimon can surely be understood as a manifestation of the Zeitgeist, but how do we understand the spirits in the second case, who have transcended the ultimate limit of finitude, death itself, and who thus rock the three Foucauldian cornerstones of finitude - life, labour, and language, "marked by the spatiality of the body, the yawning of desire, and the time of language" (Foucault, 1974:315)? Clearly, for Yeats, life is not limited by death; labour is not limited by a somnolent desire; and language is not confined within the span of a single life.

1 This article is a revised version of a paper originally delivered at the International Association for Irish Literatures Conference held at Dublin City University, 30 July - 3 August 2001. 


\section{The Daimon}

In this article I explore a strange but (in certain of its elements) central modernist relationship, that between human and Daimon, or our spirit twin. "The Daimon is our destiny" - these words indicate that our very destiny is a twinning persona. That is, fate itself is humanised in a remarkable act of colonization of this realm of potential, where energies of Chance and Choice are condensed in a twin image of ourselves. Yeats further intones that "the Daimon", though our double, "comes not as like to like but seeking its own opposite, for man and Daimon feed the hunger in one another's hearts" (Yeats, 1959:335). Or as he writes in the poem "Ego Dominus Tuus" (321):

I call to the mysterious one who yet

Shall walk the wet sands by the edge of the stream

And look most like me, being indeed my double,

And prove of all imaginable things

The most unlike, being my anti-self,

And, standing by these characters, disclose

All that I seek ...

This is the twinning of opposites, and a type of charge is set up between the opposite poles, a charge which can enrich our lives with an influx of energies perhaps not otherwise even vaguely entertained by us. This antithetical twinning is most apparent for Yeats (1959:326-327) in the distinction between one's everyday nature and one's art:

I know a famous actress who, in private life, is like the captain of some buccaneer ship holding his crew to good behaviour at the mouth of a blunderbuss, and upon the stage she excels in the representation of women who stir to pity and to desire because they need our protection, and is most adorable as one of those young queens imagined by Maeterlinck who have so little will, so little self, that they are like shadows sighing at the edge of the world.

And, regarding the creative benefits of this Daimonic energy, generated by twin forces within and without us, he writes most famously, "We make out of the quarrel with others, rhetoric, but of the quarrel with ourselves, poetry" (Yeats, 1959:331).

\section{The analytic of finitude}

It is perhaps no accident that Yeats uncovers such a momentously portentous twin at a time when what Michel Foucault calls the "analytic of finitude" is at its height. This positivist analytic displaces a sense of spiritually illumined infinity by situating "the discovery of finitude not within the thought of the infinite, but at the very heart of those contents 
that are given, by a finite act of knowing, as the concrete forms of finite existence" (Foucault, 1974:316). The notion is captured in less abstract terms by another Irish poet, Louis MacNeice, in "Bagpipe Music":

John MacDonald found a corpse, put it under the sofa,

Waited till it came to life and hit it with a poker,

Sold its eyes for souvenirs, sold its blood for whiskey,

Kept its bones for dumb-bells to use when he was fifty.

It's no go the Yogi-Man, it's no go Blavatsky,

All we want is a bank balance and a bit of skirt in a taxi.

(MacNeice, 1966:96)

The analytic tells of systems no longer bound by representations of reality, as in neoclassical thought, where organisms are represented by, for instance, classificatory scientific tables. Towards the end of the eighteenth century, Foucault would have it, horizontal representation (the classificatory table is a good example) loses its cogency as the principal means of understanding and ordering the world, or of being the episteme of that time. Instead, a new episteme emerges, based on a vertical incorporation of the very material of existence. It is as if the world is no longer understood according to external resemblance and difference, but rather according to internal structure and growth, anticipated by Coleridge with his notion of organicism. Its limits are the limits of existing structures themselves - hence Foucault's emphasis on finitude. The wondrous microcosmos, akin to Leonardo's Vitruvian man, with arms outstretched and legs akimbo, that reflects within human ambit and measure the nature of the universe, becomes in MacNeice the corpse under John MacDonald's sofa, a source of present materialist exploitation, commodified and confined to a limited area indeed.

\section{Repetition, the unthought and the Other}

The analytic of finitude finds its first characteristic in the fact of repetition, where

From one end of experience to the other, finitude answers itself .... It is within this vast but narrow space, opened up by the repetition of the positive within the fundamental, that the whole of this analytic of finitude - so closely linked to the future of modern thought - will be deployed; it is there that we shall see in succession the transcendental repeat the empirical, the cogito repeat the unthought, the return of the origin repeat its retreat (Yeats, 1959:315-316).

I interpret this passage as follows: if what is before us is all there is, what is before us must inform everything that is, including our thoughts and 
ideas. Hence our conception of the transcendental cannot be informed by something beyond, the Platonic realm of ideas, say, but must repeat or double our experience of the empirical. MacNeice's "corpse" is a macabre repetition not of Coleridge's "infinite I AM" (Coleridge, 1906: $159)$, but of the all too finite "l" of modern subjectivity.

At one point Foucault (1974:326) considers the "unthought" as an aspect of the unconscious, and so arrives at his notion of the Other:

Man has not been able to describe himself as a configuration in the episteme without thought at the same time discovering, both in itself and outside itself, at its borders yet also in its very warp and woof, an element of darkness, an apparently inert density in which it is embedded, an unthought which it contains entirely, yet in which it is also caught. The unthought (whatever name we give it) is not lodged in man like a shrivelled up nature or a stratified history; it is, in relation to man, the Other: the Other that is not only a brother but a twin, born, not of man, nor in man, but beside him and at the same time, in an identical newness, in an unavoidable duality.

He goes on,

the inexhaustible double ... presents itself to reflection as the blurred projection of what man is in his truth, but that also plays the role of a preliminary ground upon which man must collect himself and recall himself in order to attain his truth. For though the double may be close, it is alien, and the role, the true undertaking, of thought will be to bring it as close to itself as possible (Foucault, 1974:327).

\section{Daimon and Other}

It seems to me, despite the obvious differences, that the Yeatsian Daimon is a form of the Foucauldian Other, the "close" yet "alien" "double", who embodies the approach to the "unthought" conditioned by "lack" and "dread", and "upon which man must collect himself and recall himself in order to attain his truth". The most obvious difference is that the coming of the Yeatsian double is a spirited (so to speak) reaction against the analytic of finitude, not a confirmation of it. Yeats, though actually of a curiously scientific bent, experienced anxiety in the face of scientific positivism, an anxiety he ascribed in particular to the sense of fragmentation (readily enough connected to the analytic of finitude) springing from the thought of the followers of figures such as John Tyndall and T.H. Huxley (Yeats, 1961:189-90). The Daimon, in the face of this fragmentation, completes our lives, brings fullness where before there was lack. In the case of both Foucault and Yeats this double surfaces in the modernist period as a consequence of Freudian 
explorations of the unconscious; so, I would argue, the Freudian revolution is the source of both these resonant images, and this general perspective needs to be emphasised, in order not to suggest a too simplistic conflation of Yeats and Foucault. Foucault's perspective is important, though, for its inclusive nature, for its distillation of the experience of an era, as opposed to Yeats's specific and highly idiosyncratic one. That is, Foucault helps situate Yeats within the period, even as Yeats contributes to this aspect of the period in his own terms.

Through the agency of Daimonic desire, as we will see, Yeatsian spiritualism certainly repeats empirical existence. But in positing a desire that extends beyond the limits of individual human life, Yeats denies the definitive value of an exclusive finitude, such as that perceived by Foucault. This is a complex matter and warrants much more thought than I have devoted to it at present. Let me, however, point out for the time being that if Yeats, involved in a qualified manner in an aspect of the analytic of finitude, is a modernist, he is related to that type Fredric Jameson calls the "anti-modern modernist" (Jameson, 1991:304). "The various modernisms", writes Jameson, "have just as often constituted violent reactions against modernization as they have replicated its values and tendencies by their own formal insistence on novelty, innovation, the transformation of older forms, therapeutic iconoclasm and the processing of new (aesthetic) wonder-working technologies". Jameson (1991:304) illustrates his point:

If, for example, modernization has something to do with industrial progress, rationalization, reorganization of production and administration along more efficient lines, electricity, the assembly line, parliamentary democracy, and cheap newspapers - then we will have to conclude that at least one strand of artistic modernism is antimodern and comes into violent or muffled protest against modernization.

Jameson (1991:304) indicates an array of reactions against modernisation, the last of which would incorporate Yeats:

These anti-modern modernisms sometimes involve pastoral visions or Luddite gestures but are mostly symbolic, and, especially at the turn of the century, involve what is sometimes referred to as a new wave of anti-positivist, spiritualistic, irrational reactions against triumphant enlightenment progress or reason.

Though Yeats had too complex a mind to be considered merely antipositivist (as indicated in the following section), he fits in general terms into this socio-historic scheme presented by Jameson. 
In examining Daimonic desire, then, it is congruous with a reading of Yeats to do so both in terms of the empirical realm of the "dying generations", and the spiritual realm of the "artifice of eternity". In the first case, the Daimon can surely be understood as a manifestation of the Zeitgeist, but how do we understand the spirits in the second case, who have transcended the ultimate limit of finitude, death itself, and who thus rock the three cornerstones of Foucauldian finitude - life, labour, and language, "marked by the spatiality of the body, the yawning of desire, and the time of language" (Foucault, 1974:315)? Clearly, for Yeats, life is not limited by death; labour is not limited by a somnolent desire; and language is not confined within a single life-span.

Locating Yeats's supernaturalism within an historical moment is straightforward enough; but from the viewpoint of theoretical credulity, how well can one manage the strain of crossing over to the Daimonic side of this supernaturalism, to construct a spiritualist theory of desire (based on the poet's actual experience), which, while its present emergence surely has much to do with anti-modernisation as discussed above by Jameson, ultimately has deeper, more archaic roots that bypass the pressures of historical contingency. Yeats, in pre-Enlightenment fashion, conceptualised a continuity between dimensions. Consider the Neoplatonic doctrine ascribed by William Kerrigan and Gordon Braden to Marsilio Ficino: "Because of affinities between the spiritus in the human soul and the aether of the celestial spheres, Ficino reasoned, astrologically inspired images could pull down corrective influences from the daimons in the heavens" (Kerrigan \& Braden, 1989:102). In Yeats's case, this continuity was corroborated by the transitive nature of desire, and, in the present absence of any other lead, I follow this one.

\section{Spiritualism and sex}

In July 1915 a spirit who told Yeats he was his personal guide asked the poet to express his doubts about the spirit dimension in writing. The spirit would channel a reply through Yeats himself (Levine, 1983:14). The spirit in question was Leo Africanus, the sixteenth-century Spanish-Moorish geographer and poet. Despite Yeats's receptivity to such phenomena, and to indicate an early sense of antithetical play in this spiritualistic dialogism, "the exchange left Yeats sceptical, the poet doubting whether any of Leo's letters had come from beyond his own mind" (Levine, 1983:14). Leo had first manifested himself in Yeats's presence at a séance at Cambridge House, when the poet was in the company of Everard Feilding, Honorary Secretary of the Society for Psychical Research, a society that prided itself on its rigorous scientific thoroughness when it came to the investigation of matters supernatural 
(Coote, 1997:324). I mention the fact, as this society's general attitude towards the supernatural was in keeping with the poet's, though Yeats was as sceptical of the pretensions of science as of the supposed validity of certain supernatural manifestations. A cherished Yeatsian dream, for instance (which contributed towards his being expelled from the Theosophists in the previous century), was to test supernatural phenomena through scientific means, and this conditioned his approach at séances (Coote, 1997:84). In terms of the poet's relative scepticism, the most that can be said of his albeit aesthetically productive relationship with Leo was that in the end Yeats half-believed in the spirit's actual existence. However, Leo was a forerunner of the spirits that came to Yeats through his wife, George.

As far as the Yeatses were concerned, George and her Controls or Guides were responsible for many of the "factual" details recorded in $A$ Vision. George Yeats assumed the role of spirit medium in her husband's life very soon after their marriage. Most recently, Brenda Maddox (1999:71) has indicated in rather flippant vein the sexual consequences of her doing so. I find a fascinating and suggestive gloss on this in Fumiko Enchi's novel, Masks:

The state of [mediumistic] inspiration itself is intensely physical, heightening a person's sensuality to the furthest degree (unlike intellectual labour, which diminishes sexuality), so that the body of a medium in a trance comes to seem the very incarnation of sex (Enchi, 1985:77).

Whatever the reasons behind her feats, George maintained to the end that "Thomas of Dorlowicz, Ameritus, or some other of her numerous Communicators was the source of all her information, she being only the Medium or Interpreter" (Harper, 1987:x). But the Communicator Thomas and the Guide Rose wrote on 9 April 1919:

This system is not preexistent - it is developed and created by us and by you two ... we only select and our selection is subordinate to you both - therefore we are dependent on you and you influence our ability to develop and create by every small detail of your joint life (Harper, 1987:223).

Hence the dialogic intersubjectivity of the enterprise, where, in effect, desire shared across existential dimensions leads to the creation of Yeats's system. 


\section{Spiritualism and dialogism}

In communicating with the spirit Ameritus, Yeats, with himself and his wife in mind, talked, as George Mills Harper observes, "circuitously about 'the escape from objects of the emotions' 'at some moment of sexual union'" (note the formal relation between what follows and Yeatsian poetic dialogues such as "Ego Dominus Tuus"):

6. Under what circumstances do the daimons become self moving?

6. When both individuals are creative...

10. Is that the moment of the supreme activity of the daimons?

10. Yes

11. What is the moment when the two persons are self-moving in One

11. Entrance

(in Harper, 1987:369-370)

An earlier dialogic exchange emphasises the creative centrality of both Daimons and sexual desire:

1. May I take it that system is created by Third Daimon \& that the imagery is collected by First \& Second Daimon?

1. Yes

2. Do first \& second daimon to collect it make use of our senses?

2. yes of all - especially the 6 th

3. What is the sixth sense.

3. Sexual

4. How do they use the sexual sense to collect imagery.

4. To get in touch with the [personal anima mundi] \& the [anima mundi]

5. How does it bring them in touch with [the personal anima mundi and the anima mundi]

5. It makes them both male \& female \& that is necessary as the aim is bisexual

6. What do you mean by the sexual sense - define.

6. Visual desire

(in Harper, 1987:253-254)

"Sexual desire" spans dimensions and a variety of contexts, then, including the love act, the relationship between human and spirit dimensions, the creation of systemic knowledge, and a probing of the 
personal and collective unconscious (along with more arcane matter related to Jungian theories about androgyny (Jung, 1985:235) and Castiglione's Neoplatonic notion of the relation among beauty, seeing and divine union (Castiglione, 1974:304) - matters that have no bearing on the present study).

\section{Material phenomena}

The spirit dimension is not accessed solely by linguistic, dialogic means. While the majority of manifestations in séances are fraudulent, a small proportion cannot be explained away in terms of tawdry props or sleight of hand. Yeats's following account, based on first-hand experience, shows no trace of the scepticism present in the poet's encounter with Leo Africanus:

The image will begin outside the medium's body as a luminous cloud, or in a sort of luminous mud forced from the body ... One may see a vague cloud condense and diminish into a head or arm or a whole figure of a man, or to some animal shape (in Gregory, 1976: 325).

Whatever we may feel about the luminous mud, it is difficult to view as fraudulent phenomena shared among the Yeatses and their servants outside the controlled environment of the séance-room (Yeats, 1962:12). By the same token, one cannot consign George Yeats's shared experiences to the realm of "auditory hallucinations" similar to those suffered by Lacan's woman patient in the 1930s, who also "took dictations from voices" (Rajchman, 1985:21). George may have been, one supposes, the catalyst of a poltergeist-like nexus of energy, and may have somehow generated the phenomena witnessed by others, but in terms of our current knowledge this is as inexplicable as a spirit dimension.

\section{Conclusion}

Given our final bafflement in the face of the inexplicable is it valid to dismiss the Yeatsian continuum of desire, doubled through different existential or at least perceptual states, and expressed with such magisterial certitude as follows: "As man, as beast, as an ephemeral fly begets, Godhead begets Godhead,/ For things below are copies, the great Smaragdine tablet said" (Yeats, 1950:328). Although Foucault broaches the post-mortem and post-reason voices which give substance to the continuum of doubled desire, he does so within the doubly circumscribing constraints of a specifically textual finitude located within a specifically delimited period: 
in this space [of finitude] ... literature, first with surrealism ... then, and more and more purely, with Kafka, Bataille, and Blanchot, posited itself as experience: as experience of death (and in the element of death), of unthinkable thought (and its inaccessible presence) ... (Foucault, 1974:383-384).

In the end, it is Jameson's "anti-modern modernism" that comes closest to describing the general Yeatsian stance, but Jameson, in exemplifying characteristics of the term, dismissively conflates spiritualism with mere irrationalism, as we have seen (Jameson, 1991:304), thereby undercutting the credibility of the need for a reasoned explanation of the continuum of Daimonic desire inherent in Yeats. Perhaps one must rest content with this socio-historic situating of Yeatsian spiritualism, but at least, in terms of Yeats's aesthetic product, accept the power of the poetry to stir levels of being that cannot be approached through any other form of discourse. In the end it is the poetry itself that carries a charge, an energy, at odds with the mere fact of the words on the page. And this happens despite our analytical reasoning, despite our reservations about the content of certain poems. What more dramatic demonstration of the presence of Yeatsian Daimons, twining together so effectively the antithetical twins of reason and feeling, making us feel the force of topics we cannot credit?

\section{Bibliography}

Castiglione, Baldasarre. 1974. The Book of the Courtier. Transl. Thomas Hoby. London : Everyman.

Coleridge, Samuel Taylor. 1906. Biographia Literaria. London : Dent.

Coote, Stephen. 1997. W.B. Yeats: A Life. London : Sceptre.

Enchi, Fumiko. 1985. Masks. London : Arena.

Foucault, Michel. 1974. The Order of Things: An Archaeology of the Human Sciences. London : Tavistock.

Gregory, Augusta. 1976. Visions and Beliefs in the West of Ireland. Gerrards Cross : Colin Smythe.

Harper, George Mills. 1987. The Making of Yeats's A Vision. Vol. 2. London : Macmillan.

Jameson, Fredric. 1991. Postmodernism, or, the Cultural Logic of Late Capitalism. London : Verso.

Jung, C.G. 1985. Dreams. London : Ark Paperbacks.

Kerrigan, William \& Gordon Braden. 1989. The Idea of the Renaissance. Baltimore : Johns Hopkins University Press.

Levine, Herbert. 1983. Yeats's Daimonic Renewal. Ann Arbor : UMI Research Press.

MacNeice, Louis. 1966. Collected Poems. London : Faber.

Maddox, Brenda. 1999. George's Ghosts: A New Life of W.B. Yeats. London : Picador.

Rajchman, John. 1985. Michel Foucault: The Freedom of Philosophy. New York : Columbia University Press.

Yeats, W.B. 1950. Collected Poems. London : Macmillan.

Yeats, W.B. 1959. Mythologies. London : Macmillan. 
Yeats, W.B. 1961. Essays and Introductions. London: Macmillan.

Yeats, W.B. 1962. A Vision. (Revised version.) London : Macmillan.

\section{Key concepts:}

daimons

modernist aesthetics

spiritualism

unconscious, the

Kernbegrippe:

demone

onbewuste, die

modernistiese estetika

spiritualisme 